\title{
Urogenital vasculature and local steroid concentrations in the uterine branch of the ovarian vein of the female tammar wallaby (Macropus eugenii)*
}

\author{
P. A. Towers $\dagger$, G. Shaw and M. B. Renfree \\ $\dagger$ Department of Physiology, University of Queensland, St Lucia, Queensland 4067, and \\ Department of Anatomy, Monash University, Clayton, Victoria 3168, Australia
}

\begin{abstract}
Summary. The urogenital vasculature of the tammar comprises 4 major paired arteries and veins: the ovarian, the cranial urogenital, the caudal urogenital and the internal pudendal artery and vein. The ovarian artery and vein and their uterine branches which supply the ovary, oviduct and uterus, ramify extensively. Each anterior urogenital artery and vein supplies the caudal regions of the ipsilateral uterus, lateral and median vagina and cranial parts of the urogenital sinus. The caudal urogenital arteries and veins supply the urogenital sinus and caudal regions of the bladder. The internal pudendal artery and vein vascularize the cloacal region, with some anastomoses with branches of the external pudendal vessels. Anastomoses connect the uterine branch of the ovarian artery with the uterine branch of the cranial urogenital and cranial branches of the caudal urogenital arteries, and connect the caudal urogenital and the internal pudendal arteries. Anastomotic connections between the left and right arterial supply also occur across the midline of the cervical regions of the uteri and the anterior lateral vaginae. Similar connections are seen in the venous system.

The uterine branch of the ovarian artery ramifies extensively very close to the ovary, giving a plexiform arrangement with the ovarian veins, and also with the uterine venous system on the lateral side of each uterus. This plexiform structure provides an anatomical arrangement which could allow a local transfer of ovarian hormones from ovarian vein into the uterine arterial supply, and thence to the ipsilateral uterus. Progesterone concentrations in plasma from the mesometrial side of the uterine branch of the ovarian vein are markedly higher than in tail vein plasma, especially during the 'Day 5 peak' early in pregnancy, and also at full term. There is also a marked decrease in progesterone concentration from all sites immediately before birth as previously reported for peripheral plasma. These results support the suggestion of a countercurrent transfer mechanism, at least for progesterone, and possibly other hormones, between the ovarian vein and uterine artery. Such a local transfer could explain the different morphological responses of the endometria of the two adjacent uteri during pregnancy in macropodid marsupial species.
\end{abstract}

\section{Introduction}

The anatomy of the blood vasculature of the female reproductive tract of the ewe, cow, mare, sow, laboratory rodents, monkeys and also dogs and cats is well known (e.g. Ginther, 1976; Lee \& O'Shea, 1976; Hossain \& O'Shea, 1983) but comparable studies of female marsupial vasculature

\footnotetext{
*Reprint requests to Dr M. B. Renfree.
} 
have been restricted to a single report on a phalangerid, the brush possum (Trichosurus vulpecula), along with brief descriptions of some other marsupial species (Lee \& O'Shea, 1977). In several eutherian mammals physiological and anatomical evidence suggests that a local hormone transfer from the uterus to the ovary may be responsible for luteolysis at the end of each oestrous cycle (Challis, 1979). Ginther (1974) has shown that close apposition of the ovarian artery and vein occurs in species which have this local uterine luteolytic mechanism. However, this generalization does not hold for marsupials, because, although the ovarian artery is closely coiled around the ovarian vein in the brush possum (Lee \& O'Shea, 1977), there is no uterine luteolytic mechanism in this species (Clark \& Sharman, 1965) or in the opossum, Didelphis virginiana (Hartman, 1925).

This close vascular association in the marsupials may, however, have a functional role. Marsupials have two anatomically separate uteri, each with its own cervix opening into the anterior vaginal cul-de-sac (Tyndale-Biscoe, Hearn \& Renfree, 1974; Tyndale-Biscoe \& Renfree, 1986). The brush possum and the tammar wallaby (Macropus eugenii) are monovulatory species. During the luteal phase of the brush possum's oestrous cycle, the uterus ipsilateral to the corpus luteum increases in weight by up to $19 \%$, compared to a $1 \%$ increase in the weight of the contralateral uterus (Von der Borch, 1963). Similarly, in the tammar wallaby, uterine endometria are always heavier on the side of an active corpus luteum, during the first half of the oestrous cycle, and in early pregnancy (Renfree \& Tyndale-Biscoe, 1973). A similar local stimulation of the uterus ipsilateral to the corpus luteum occurs during the first 18 days of delayed gestation in another macropodid, the potoroo (Potorous tridactylus) (Shaw \& Rose, 1979).

These unilateral stimuli early in the cycle or pregancy are distinct from the feto-placental stimulation of the gravid uterus, which is seen only in the last third of pregnancy in the tammar wallaby (Renfree, 1972). They are presumably due to local effects of luteal secretions, since hormones in the peripheral circulation would be expected to act equally on both of the separate uteri. Einer-Jensen \& McCracken (1981) have demonstrated that in the ewe progesterone (and presumably other steroids) can be transferred by a local countercurrent mechanism, from the ovarian vein into the ovarian artery. A similar countercurrent transfer has also been observed in the sow ovarian vascular pedicle (Krzymowski, Kotwica \& Stefańczyk, 1981). The unilateral uterine stimulation seen in marsupials could be accounted for if there were a similar local transfer of luteal steroids into the uterine arterial supply.

Very little is known of the steroid concentrations in the ovarian drainage. In the tammar wallaby, there is a significantly higher concentration of oestradiol-17 $\beta$ in the ovarian vein draining the reproductive organs when collected from the side with the Graafian follicle than from the other ovarian vein or the peripheral circulation (Harder, Hinds, Horn \& Tyndale-Biscoe, 1984). In the brush possum, Curlewis, Axelson \& Stone (1985) demonstrated that plasma samples from the ovarian vein ipsilateral to the follicle contained more oestradiol than does peripheral plasma during the follicular phase, whilst progesterone concentrations in ovarian vein plasma were much higher than in peripheral plasma during the luteal phase.

Lee \& O'Shea (1977) suggest that the intimate structural relationship in the possum between ovarian arteries and veins may be a specialization for countercurrent exchange between venous and arterial blood. This study was undertaken to describe the vasculature of the reproductive system of the female tammar to determine whether an anatomical basis for a local hormone pathway between the corpus luteum and its ipsilateral uterus exists, and to provide preliminary data on progesterone concentrations in this system as compared to peripheral plasma values.

\section{Materials and Methods}

Animals. Tammar wallabies were obtained from Kangaroo Island, South Australia. They were kept, at Murdoch University, Perth, Western Australia, or at Monash University, Melbourne, Victoria, in grassed, outside yards and fed supplementary lucerne, hay and oats ad libitum. A 
continuous supply of water was available. Animals at known stages of gestation were obtained by terminating lactational diapause by removing pouch young (Renfree \& Tyndale-Biscoe, 1973). Birth usually occurs about 27 days later (Tyndale-Biscoe \& Renfree, 1986).

Gross anatomy. Fresh dissection and infusion techniques were used to determine the vascular anatomy of the reproductive tracts of 14 female tammars. The infusion compounds used were an acrylic resin (Weld-on 40: Industrial Polychemical Service, CA, U.S.A.), a silicone rubber injection compound (Microfil: Canton Biomedical Products Inc, CO, U.S.A.) and Latex (Dunlop Rubber Co., Melbourne, Australia).

(a) Acrylic resin. Animals were overdosed with $10 \mathrm{ml}$ pentobarbitone sodium $(62.5 \mathrm{mg} / \mathrm{ml})$ containing 1000 i.u. heparin/ml (Heparin: Commonwealth Serum Laboratories, Australia). The acrylic resin (with a red pigment) was infused through a cannula into the aorta. The ventricles of the heart were opened to allow drainage of blood. Blue pigmented resin was then infused into the caudal vena cava. Infused tissues were dissolved in concentrated $\mathrm{HCl}$ and the cast washed.

(b) Silicone and latex rubber. Immediately post mortem, silicone rubber (Microfil) with a yellow pigment, or Latex (white), was injected either into the caudal aorta or into the ovarian vein, close to its junction with the vena cava. The venous system has numerous, efficient valves which prevent flow of the solutions into any but the major veins, so blood was allowed to clot after a ligature was applied to the caudal vena cava just below the renal veins. The silicone rubber and Latex casts were fully set after $24 \mathrm{~h}$ at $5^{\circ} \mathrm{C}$, but remained flexible, enabling detail of both arterial (Microfil or Latex filled) and venous (filled with Microfil or clotted blood) anatomy to be examined by dissection. Specimens were dehydrated and cleared with benzyl benzoate (Del Campo, Steffenhagen \& Ginther, 1974), or kept cold at $5^{\circ} \mathrm{C}$ and dissected and photographed whilst still fresh.

Anatomical nomenclature. We use the nomenclature of Lee \& O'Shea (1977) for the blood vessels supplying the urogenital system of marsupials. The Nomina Anatomica Veterinaria (Schaller, Habel \& Frewein, 1973) which is based on eutherian species of mammal, is not appropriate for marsupials because of the very different reproductive tract anatomy (Fig. 1). Lee \& O'Shea (1977) propose the closest corresponding terms.

Collection of blood samples. Peripheral blood was obtained from the tail vein or by cardiac puncture. Uterine vein blood was obtained at laparotomy under halothane anaesthesia (see Young \& Renfree, 1979). The reproductive tract was elevated and the ovary held so that the blood vessels in the ligaments between the ovary and the uterus were clearly visible. Blood was withdrawn from the larger mesometrial vessels of the uterine branch of the ovarian vein into a syringe with a 26-gauge needle. Use of this sampling site precludes the possibility of obtaining blood from the ovarian drainage. The ovary which bore the corpus luteum was recorded, as was the presence of an embryo. Blood was centrifuged at $1250 \mathrm{~g}$ at $4^{\circ} \mathrm{C}$ for $15 \mathrm{~min}$, and the plasma was stored at $-20^{\circ} \mathrm{C}$.

Radioimmunoassay. Progesterone and oestradiol-17 $\beta$ were measured in plasma by radioimmunoassays previously described for the tammar (progesterone: Ward \& Renfree, 1984; oestradiol: Shaw \& Renfree, 1984). For progesterone, the sensitivity of the assay was $11 \mathrm{pg} / \mathrm{ml}$ and the intra- and inter-assay coefficients of variation were $17 \%$ and $22 \%$ respectively. These slightly higher variation values were due to the extreme ranges of concentrations measured in the samples. For oestrogen, the sensitivity of the assay was $2-4 \mathrm{pg} / \mathrm{ml}$ and the intra- and inter-assay coefficients of variation were $12 \%$ and $14 \%$ respectively.

\section{Results}

Anatomy

Differences between the eutherian and marsupial urogenital blood vascular anatomy are attributable largely to the different anatomy of the reproductive tracts, derived from a different 


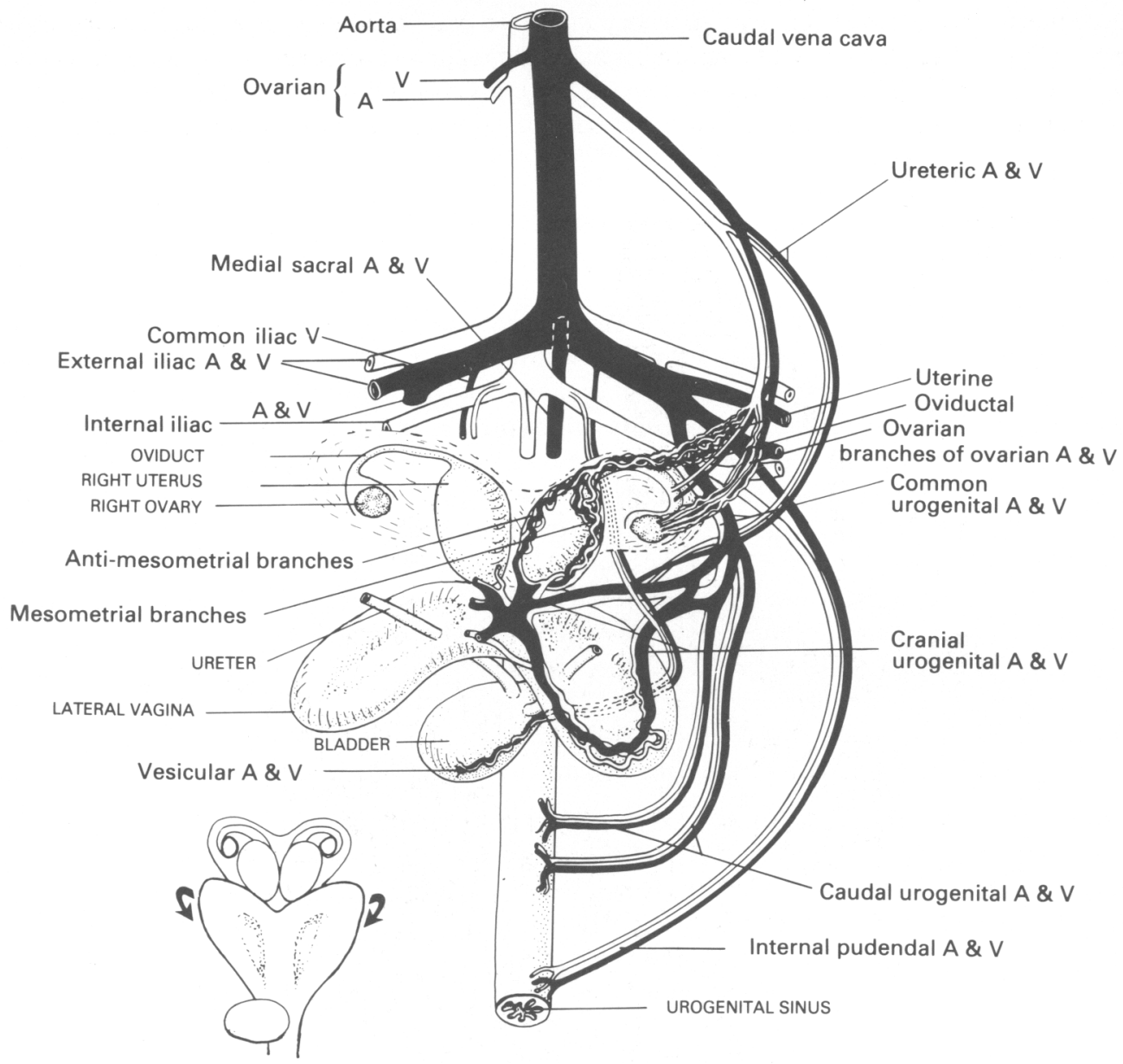

Fig. 1. Semi-diagrammatic representation of the ventral aspect reproductive tract of a female tammar showing the two separate uteri and two lateral vaginae plus median vagina distinctive of marsupials; the lateral vaginae have been deflected caudally (see diagram lower left hand corner) to allow display of the arterial supply and venous drainage of the urogenital tract. Not to scale: relationships and sizes of the blood vessels have been exaggerated to clarify positions. See Fig. 2 for exact scaling.

migration of the urinary ducts around the genital ducts in the early embryo (Tyndale-Biscoe, 1973). Four paired arteries and veins supply the marsupial reproductive tract: the ovarian artery and vein, cranial and caudal urogenital arteries and veins, and the internal pudendal artery and vein (Lee \& O'Shea, 1977). These correspond approximately to the ovarian, the uterine, the vaginal and the internal pudendal arteries and veins of eutherian mammals as defined by Nomina Anatomica Veterinaria. The latter body also recommended that the term 'utero-ovarian' is no longer used.

In the tammar the left ovarian artery arises from the aorta separately but close to the right ovarian artery (Figs $1 \& 2$ ). The fine ureteric vessels branch off about one third of the way to the ovary: these vessels are easily broken. Each ovarian artery follows a fairly direct path to the ipsilateral ovary. About half way to the ovary, and $1.5 \mathrm{~cm}$ below the ureteric branches, each branches over the next $2 \mathrm{~cm}$ to supply the adjacent uterus and oviduct (Fig. 2). Both the ovarian 
and the uterine branches of the ovarian artery ramify to become a leash of vessels running closely together (Figs 1, $2 \& 3$ ). The small ovarian branches are relatively uniform in size and run relatively straight for several millimeters and then become tortuous and spiral (Fig. 3). Multiple branches of the uterine branch pass laterally down both sides of each uterus. The mesometrial branches are

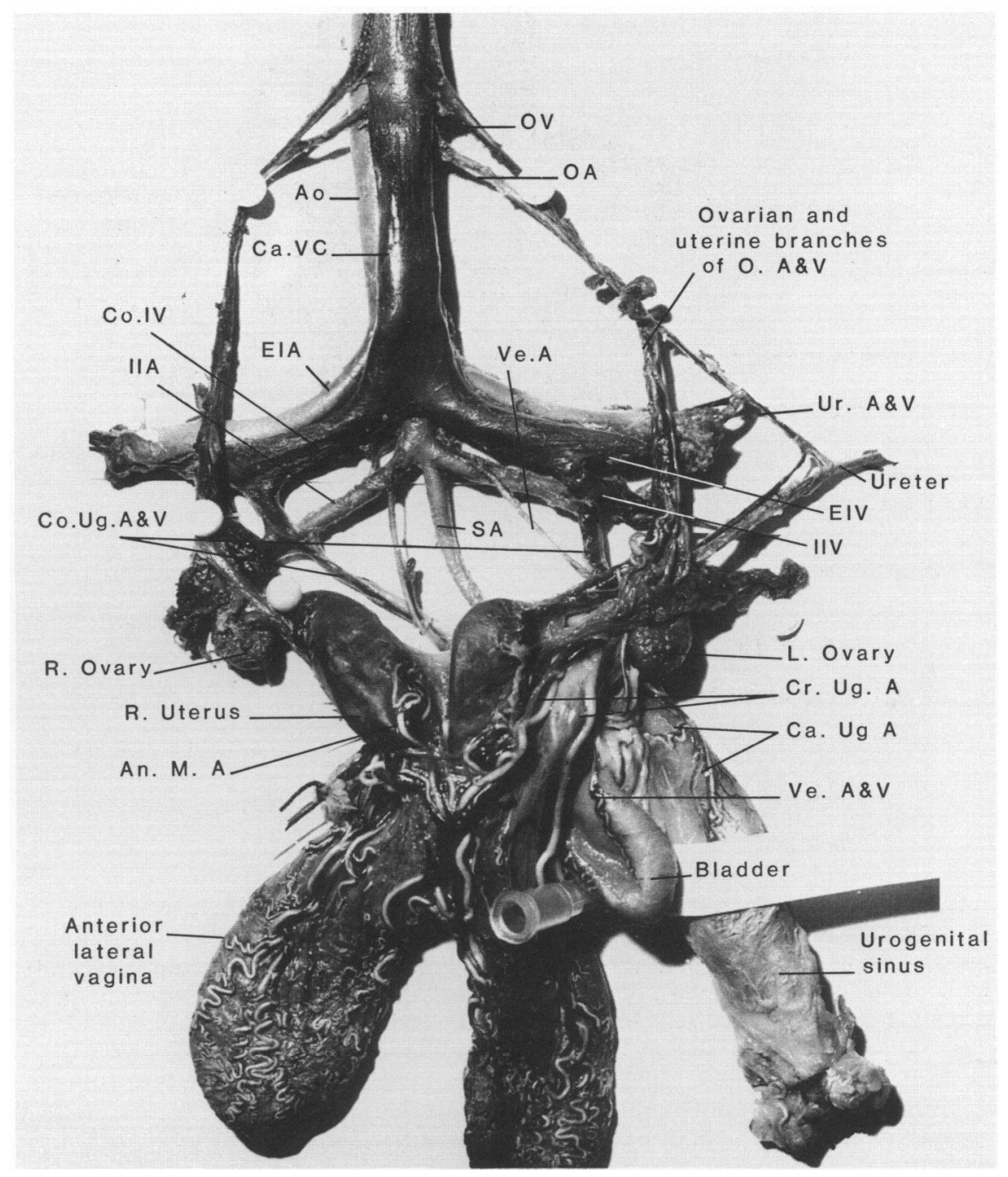

Fig. 2. Photograph of the tract after Latex infusion of the arterial system (white) from which Fig. 1 was largely drawn. Vessels appear enlarged due to the pressure of injected material. The veins contain clotted blood (dark). Arteries (white): An.M.A. = anti-mesometrial artery, Ao $=$ caudal aorta, Ca.Ug.A = caudal urogenital artery, Co.Ug.A = common urogenital artery, Cr.Ug.A = cranial urogenital artery, EIA = external iliac artery, IIA = internal iliac artery, IPA = internal pudendal artery, $\mathrm{L}=$ left, $\mathrm{OA}=$ ovarian artery, $\mathrm{R}=$ right, $\mathrm{S} . \mathrm{A} .=$ sacral artery, Ur.A = ureteric artery, Ve.A = vesicular artery. Veins (black): Ca.Ug.V = caudal urogenital vein, $\mathrm{Ca} . \mathrm{VC}=$ caudal vena cava, $\mathrm{Co} . \mathrm{IV}=$ common iliac vein, $\mathrm{Co} . \mathrm{Ug} . \mathrm{V}=$ common urogenital vein, Cr.Ug.V = cranial urogenital vein, EIV = external iliac vein, IIV = internal iliac vein, IPV = internal pudendal vein, $\mathrm{OV}+$ ovarian vein, $\mathrm{Ur} . \mathrm{V}=$ ureteric vein, $\mathrm{Ve} . \mathrm{V}=$ vesicular vein.

This specimen is from an oestrous animal and hence the lateral vaginae are enlarged. 


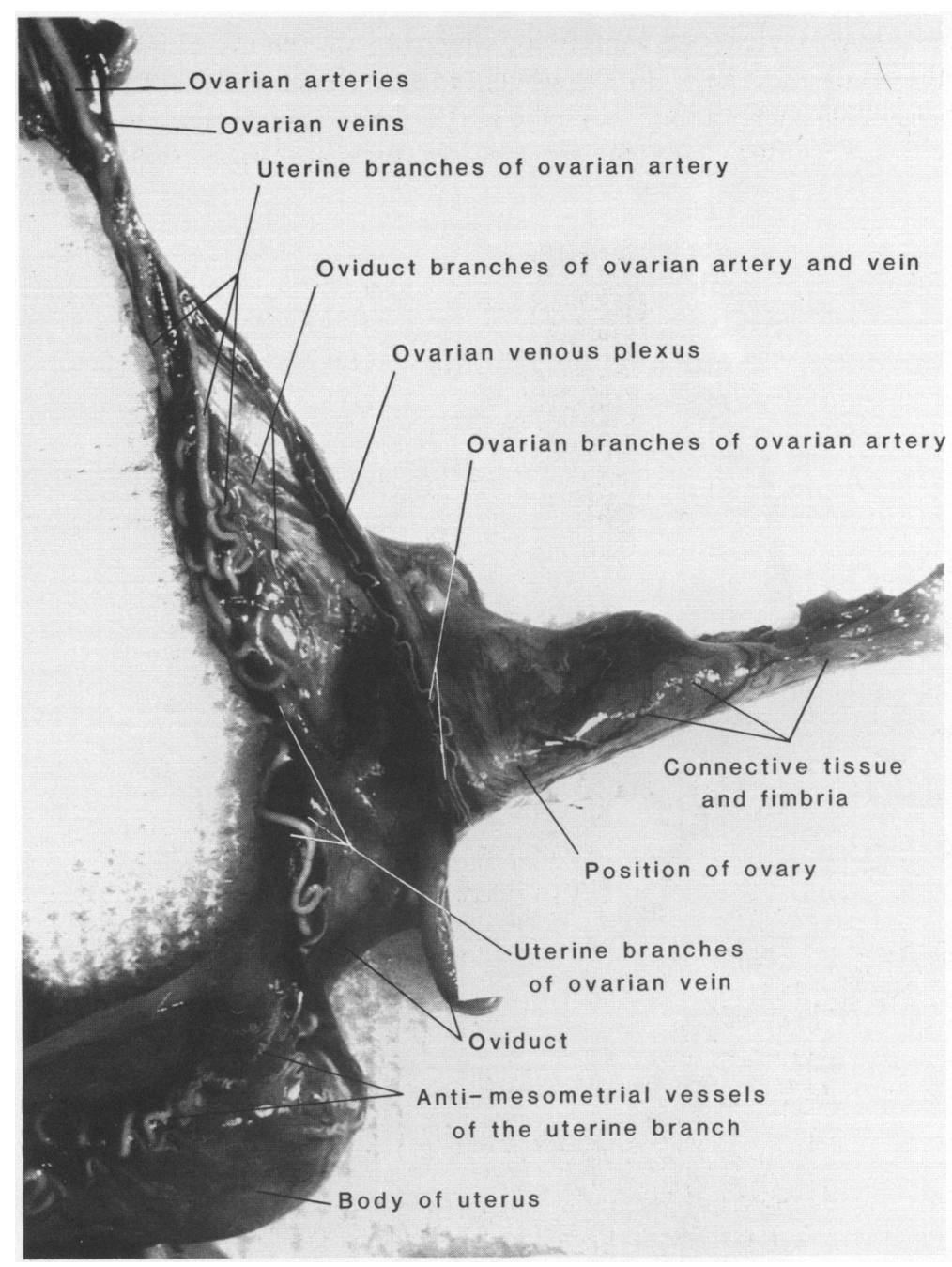

Fig. 3. Close-up photograph of the ovarian vasculature within $2 \mathrm{~cm}$ of the ovary. The ovarian branches have been dissected free from the uterine branches of the ovarian vein, but in the living animal these are in close juxtaposition within the same mesentery (see also Fig. 5). The ureteric branches join the ovarian vessels. The ovarian arterial branches surrounding the uterine branch of the ovarian vein, and the uterine arterial supply runs very close to the ovary and its venous drainage. The body of the uterus is $1.0-\mathrm{cm}$ wide.

larger than those on the anti-mesometrial borders of each uterus, but both branches give off small vessels at right angles which run on the surface of each uterus. Branches of the cranial urogenital artery anastomose with the uterine branch of the ovarian artery at the caudal end of the uterus.

The left ovarian vein usually terminates at the caudal vena cava just caudal to the right ovarian vein, and is formed by a fusion of a plexiform group of veins draining the ovary, uterus and oviduct. Venous drainage from the oviduct joins with drainage from the ipsilateral uterus before the junction with the ovarian branch of the ovarian vein (Figs $1 \& 2$ ). The ovarian branch of the ovarian vein forms a venous plexus which is covered at its proximal end by the multiple branches of the uterine and ovarian branches of the ovarian artery (Fig. 3). Histological sections were taken of 
this plexus and show a close association of arterial and venous vessels. The ovarian veins terminated at the caudal vena cava close to where the ovarian arteries branches from the aorta.

The external iliac arteries branch from the aorta about $3 \mathrm{~cm}$ below the origin of the ovarian arteries (Figs 1, 2, 4 \& 5). Just caudal the aorta terminates at the origin of the internal iliac arteries

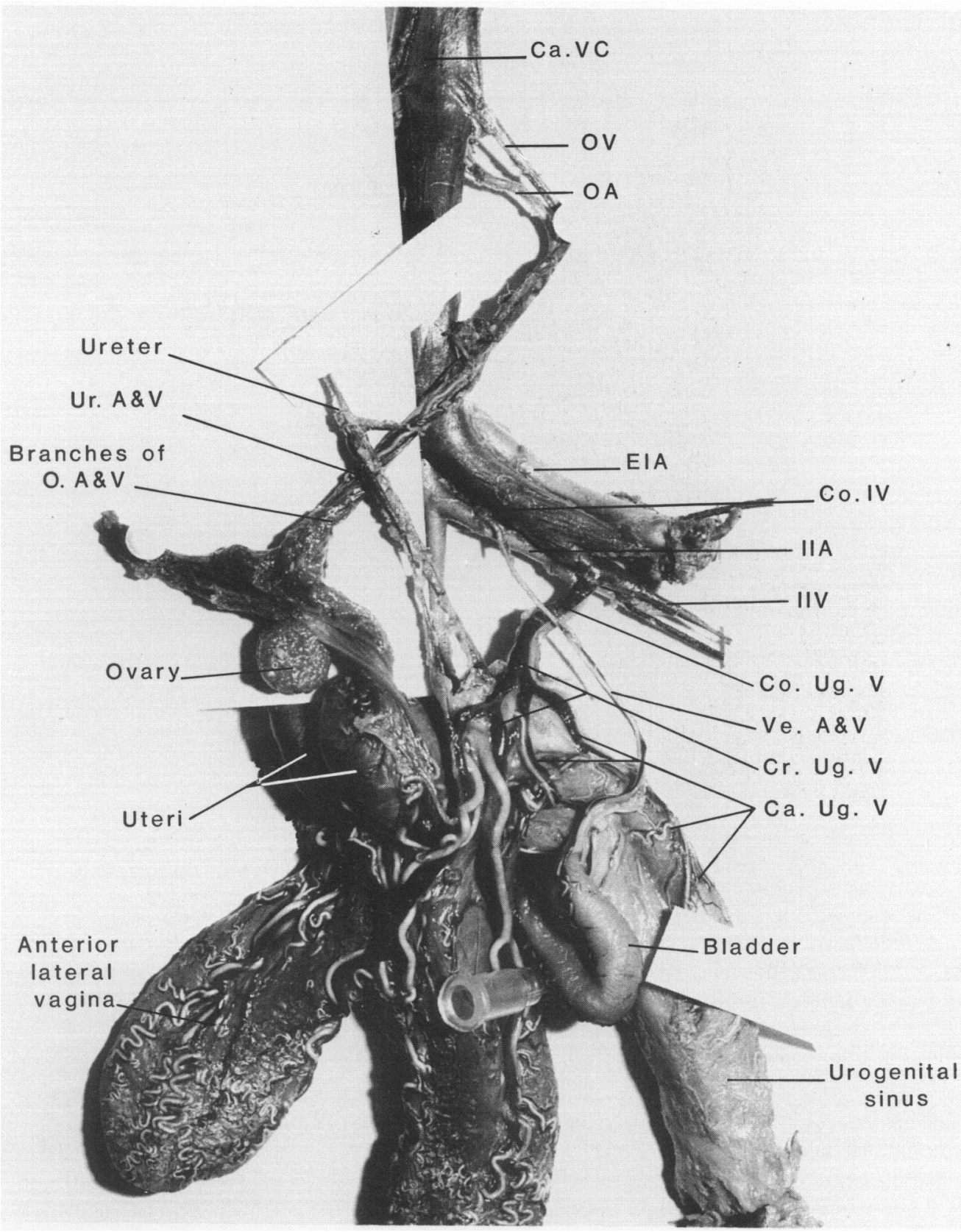

Fig. 4. Photograph of the urogenital arteries and veins, with the left ovary and lateral vagina displaced ventrally to show the vessels which normally run underneath (dorsally) these structures (labels as in Fig. 1). 


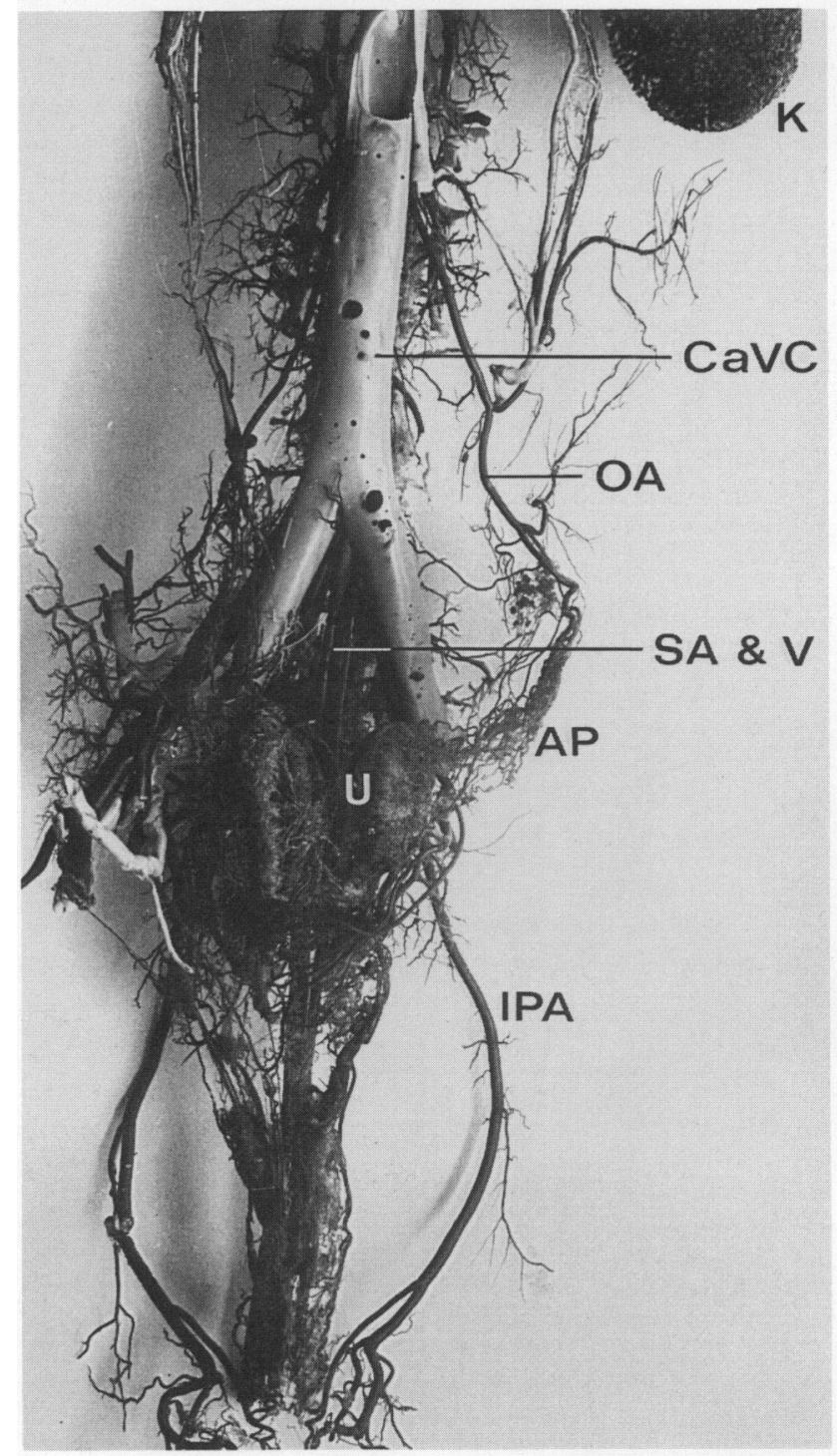

Fig. 5. Acrylic cement cast of the vascular system (arteries: darker, veins: lighter) after maceration and trimming, showing the arterial plexus of the ovarian vessels, the arterial supply to the reproductive system and the internal pudendal artery which passes around the hip joint before supplying the urogenital sinus. The median sacral vein, which is not visible in Fig. 1(b), is clearly shown. The ovarian artery runs parallel to the ovarian vein, which is seen only where it joins the caudal vena cava. Note the plexiform arrangement of the arteries in the region of the ovary and uterus. The acrylic did not pass into the venous plexus due to the valves, but the veins parallel the arteries.

$\mathrm{AP}=$ arterial plexus, $\mathrm{K}=$ kidney, $\mathrm{U}=$ arteries of the uteri. Other lettering as in Fig. 1. 
and the median sacral artery. The external and internal iliac veins fuse to form a common iliac vein. The median sacral vein joins with one of the common iliac veins near this junction, usually on the left side, at the formation of the caudal vena cava (Figs $1,2 \& 5$ ).

The cranial urogenital arteries are the first major branches from the internal iliac arteries. These branch close to their origin giving rise to a cranial and a caudal branch. The cranial branch gives a supply to the uterus, the anterior vaginal cul-de-sac and both the lateral and median vaginae (Figs $1,2 \& 4)$. The caudal branch supplies the caudal regions of both the lateral and median vaginae, and the anterior regions of the bladder. The cranial urogenital veins closely follow the corresponding arteries. Anastomoses occur between the uterine branch of the cranial urogenital artery and the uterine branch of the ovarian artery, and also between the corresponding veins (Figs 1, 2 \& 4).

The internal iliac artery bifurcates to form the caudal urogenital and the internal pudental arteries (Fig. 5). The caudal urogenital artery runs cranially to supply the caudal region of the bladder and to supply the urogenital sinus, where it anastomoses with caudal branches of the cranial urogenital artery. The internal pudendal artery and branches from the external iliac artery supply the cloacal region. Small anastomoses with caudal branches of the caudal urogenital artery occur just cranial to the cloaca. The cranial regions of the bladder are supplied by the paired vesicular arteries which arise from the internal iliac arteries and travel by a fairly direct path to the bladder (Figs $1 \& 2$ ). The corresponding vein passes similarly to the respective common iliac vein.

The caudal urogenital vein and the internal pudendal vein drain regions of the urogenital tract supplied by the corresponding arteries, and have corresponding anastomotic connections. Other anastomoses in both the arterial and venous systems connect one side to the other (Figs 1, 2 \& 5).

\section{Steroid concentrations}

Concentrations of oestradiol-17 $\beta$ in the peripheral plasma and in the uterine branches of the ovarian vein were all below $10 \mathrm{pg} / \mathrm{ml}$ at the days sampled after removal of pouch young (Days 7, 9, $18,21 \& 25$; insufficient blood was collected on the other days sampled to allow assay of both progesterone and oestradiol) which were all earlier than the post-partum rise which usually occurs at Day 27-28. Plasma progesterone concentration was markedly higher in the uterine vein (mesometrial branch) ipsilateral to the active corpus luteum than in the contralateral uterine vein or the

Table 1. Concentrations $(\mathrm{pg} / \mathrm{ml})$ of progesterone collected from each mesometrial side of the uterine branch of the ovarian vein compared with peripheral plasma collected from the tail vein after removal of pouch young (RPY)

\begin{tabular}{lccccc}
\hline $\begin{array}{c}\text { Day after } \\
\text { RPY }\end{array}$ & $\begin{array}{c}\text { No. of } \\
\text { tammars }\end{array}$ & CL side & $\begin{array}{c}\text { Follicle } \\
\text { side }\end{array}$ & $\begin{array}{c}\text { Peripheral } \\
\text { plasma }\end{array}$ & $\begin{array}{c}\text { Ratio } \\
\text { Side:peripheral } \\
\text { plasma }\end{array}$ \\
\hline 0 & 5 & $518 \pm 246$ & $329 \pm 63$ & $224 \pm 52$ & $2 \cdot 3: 1$ \\
5 & 4 & $2768 \pm 582^{* \dagger}$ & $440 \pm 96$ & $416 \pm 101$ & $6 \cdot 6: 1$ \\
7 & 7 & $720 \pm 101 \dagger$ & $606 \pm 127 \dagger$ & $420 \pm 58$ & $1 \cdot 7: 1$ \\
9 & 4 & $1670 \pm 725^{* \dagger}$ & $549 \pm 134$ & $360 \pm 126$ & $4 \cdot 6: 1$ \\
10 & 4 & $1498 \pm 551 \dagger$ & $1181 \pm 423$ & $633 \pm 67$ & $2 \cdot 4: 1$ \\
$14 \& 15$ & 5 & $1656 \pm 266^{* \dagger}$ & $1198 \pm 88 \dagger$ & $659 \pm 96$ & $2 \cdot 5: 1$ \\
$20 \& 21$ & 7 & $1200 \pm 238$ & $1120 \pm 217$ & $1095 \pm 277$ & $1 \cdot 1$ \\
$23 \& 24$ & 2 & $1110 \pm 1$ \\
25 & 7 & $2478 \pm 1087$ & $1595 \pm 298 \dagger$ & $1076 \pm 93$ & $2 \cdot 5: 1$ \\
$26 \& 27$ & 5 & $994 \pm 240+$ & $753 \pm 181 \dagger$ & $314 \pm 121$ & $3 \cdot 2: 1$ \\
31 & 11 & - & - & $480 \pm 68$ & -1 \\
\hline
\end{tabular}

Values are mean \pm s.e.m.

*Different from contralateral side $(P<0.05, t$ test $)$.

$\dagger$ Different from peripheral plasma $(P<0.05, t$ test $)$. 
peripheral blood in most samples (Table 1). A very sharp increase was observed at Day 5 , and concentrations were again high by Day 25, 1 or 2 days before birth. Progesterone concentrations from all three sites showed the usual sharp decline on the day of expected births (Day 27). The ratios of concentrations of progesterone collected from the mesometrial uterine vein on the side of the corpus luteum to that of peripheral plasma ranged between $1 \cdot 1: 1$ at Day 20 to $6 \cdot 6: 1$ at Day 5 (Table 1).

\section{Discussion}

The urogenital vasculature of the tammar wallaby is similar to that of some other macropodid species, and the brush possum (Lee \& O'Shea, 1977). The cranial and caudal urogenital vessels of at least one specimen of $M$. rufus, $M$. giganteus and Vombatus arose by common trunks from the internal iliac vessels (Lee \& O'Shea, 1977) as did those of quokkas (Setonix brachyurus) and agile wallabies ( $M$. agilis) (P. A. Towers, unpublished results), unlike those of the brush possum. All the macropodids have ovarian veins and arteries which run in close apposition.

The ovarian vein is a fusion of a plexiform group of small veins draining the ovary, the cranial end of the uterus and the oviduct. The multiple uterine branches of the ovarian artery almost completely cover the uterine and ovarian branches of the ovarian vein, as is seen also in the brush possum (Lee \& O'Shea, 1977). Although no portal blood supply from the ovary to the uterus was observed, because of the proximity of the branched uterine arterial supply to the ovarian drainage, it would seem possible for hormones of luteal origin to diffuse from the ovarian vein into these arteries, possibly by a countercurrent system, and thus preferentially stimulate the ipsilateral uterus. In the ewe such a countercurrent transfer mechanism has been demonstrated for the passage of progesterone between the ovary and the uterus (Einer-Jensen \& McCracken, 1981). Lee \& O'Shea (1977) and Shaw \& Rose (1979) suggest likewise that the vascular plexi seen in the brush possum and the potoroo respectively may be important for the unilateral uterine stimulations seen in these species.

The present study provides the first preliminary evidence for the possible physiological significance of this vascular arrangement. Blood collected from the uterine branch of the ovarian vein ipsilateral to the active corpus luteum had a substantially higher concentration of progesterone than blood from the peripheral circulation or than the corresponding contralateral uterine branch, indicating that the progesterone from the corpus luteum can preferentially pass into the ipsilateral uterine arterial supply. Such high concentrations are probably of physiological significance. However, since no estimates of blood flow rates were obtained from the vessels sampled we cannot quantify steroid production or transfer rates. The highest uterine vein progesterone concentrations were seen at Day 5, when there is a peak of luteal progesterone production (Hinds, Evans \& Tyndale-Biscoe, 1983), whilst there is still little apparent increase in ovarian and uterine blood flow. Later in the luteal phase there is great enlargement of the urogenital vasculature presumably stimulated by the elevated concentrations of ovarian steroids. The presumed increased blood flow may lower the progesterone concentrations in ovarian venous plasma towards those in the systemic circulation. The high levels seen in some blood samples from the follicular side uterine vein are possibly artefactual. Blood from the CL side may have passed through the anastomosing vessels at the caudal end of the uterus to the follicular side due to partial occlusion of the drainage from the CL side during sampling. However in-situ dye infusions provided no evidence for substantial cross-flow in the normal situation.

While these results are suggestive that the intimate structural relationships between the ovarian arteries and veins have physiological significance, and appear to explain the unilateral uterine effects observed in monovulatory species, further studies need to be made of the precise routes and the mechanisms by which substances may be transferred from ovary to uterus, and uterus to ovary. 
We thank Dr T. P. Fletcher for assay of the Day-10 and Day-14 plasma progesterone samples; Mr G. I. Wallace and Dr I. R. Young for preliminary dissections of the quokka and tammar; Ainslie Brown for assistance; Dr J. D. O'Shea for his advice and criticism of the manuscript. This study was supported by grants from the Australian Research Grants Scheme.

\section{References}

Challis, J.R.G. (1979) Prostaglandins. In Reproduction in Mammals, Vol. 7. Mechanisms of Hormone Action, ch. 3, pp. 81-116. Eds C. R. Austin \& R. V. Short, Cambridge University Press.

Clark, M.J. \& Sharman, G.B. (1965) Failure of hysterectomy to affect the ovarian cycle of the marsupial, Trichosurus vulpecula. J. Reprod. Fert. 10, 459-461.

Curlewis, J.D., Axelson, M. \& Stone, S.M. (1985) Identification of the major steroids in ovarian and adrenal venous plasma of the brushtail possum (Trichosurus vulpecula) and changes in the peripheral plasma levels of oestradiol and progesterone during the reproductive cycle. $J$. Endocr. 105, 53-62.

Del Campo, C.H., Steffenhagen, W.P. \& Ginther, O.J. (1974) Clearing techniques for preparation and photography of anatomic specimens of blood vessels of female genitalia. Am. J. vet. Res. 35, 303-310.

Einer-Jensen, N. \& McCracken, J.A. (1981) The transfer of progesterone in the ovarian vascular pedicle of the sheep. Endocrinology 109, 685-690.

Ginther, O.J. (1974) Internal regulation of physiological processes through local venoarterial pathways: a review. J. Anim. Sci. 39, 550-564.

Ginther, O.J. (1976) Comparative anatomy of uteroovarian vasculature. Scope (Veterinary) $\mathbf{X X}, 1-17$.

Harder, J.D., Hinds, L.A., Horn, C.A. \& Tyndale-Biscoe, C.H. (1984) Oestradiol in follicular fluid and in utero-ovarian venous and peripheral plasma during parturition and post-partum oestrus in the tammar, Macropus eugenii. J. Reprod. Fert. 72, 551-558.

Hartman, G.C. (1925) Hysterectomy and the oestrous cycle in the opossum. Am. J. Anat. 35, 25-29.

Hinds, L.A., Evans, S.M. \& Tyndale-Biscoe, C.H. (1983) In-vitro secretion of progesterone by the corpus luteum of the tammar wallaby, Macropus eugenii. $J$. Reprod. Fert. 67, 57-63.

Hossain, M.I. \& O'Shea, J.D. (1983) The vascular anatomy of the ovary and the relative contribution of the ovarian and uterine arteries to the blood supply of the ovary in the guinea pig. J. Anat. 137, 457-466.

Krzymowski, T., Kotwica, J. \& Stefańczyk, S. (1981) Venous-arterial counter-current transfer of $\left[{ }^{3} \mathrm{H}\right]$ testosterone in the vascular pedicle of the sow ovary. $J$. Reprod. Fert. 61, 317-323.
Lee, C.S. \& O'Shea, J.D. (1976) The extrinsic blood vessels of the ovary of the sheep. $J$. Morph 148, $287-304$.

Lee, C.S. \& O'Shea, J.D. (1977) Observations on the vasculature of the reproductive tract in some Australian marsupials. J. Morph. 159, 95-114.

Renfree, M.B. (1972) Influence of the embryo on the marsupial uterus. Nature, Lond. 240, 475-477.

Renfree, M.B. \& Tyndale-Biscoe, C.H. (1973) Intrauterine development after diapause in the marsupial Macropus eugenii. Devl Biol. 32, 28-40.

Schaller, O., Habel, R.E. \& Frewein, J. (Eds) (1973) Nomina Anatomica Veterinaria, 2nd edn. Int. Committee on Veterinary Anatomical Nomenclature, Vienna.

Shaw, G. \& Renfree, M.B. (1984) Concentrations of oestradiol-17 $\beta$ in plasma and corpora lutea throughout pregnancy in the tammar, Macropus eugenii. $J$. Reprod. Fert. 72, 29-37.

Shaw, G. \& Rose, R.W. (1979) Delayed gestation in the potoroo, Potorous tridactylus (Kerr). Aust. J. Zool. 27, 901-912.

Tyndale-Biscoe, C.H. (1973) Life of Marsupials. Edward Arnold, London.

Tyndale-Biscoe, C.H. \& Renfree, M.B. (1986) Reproductive Physiology of Marsupials. Cambridge University Press.

Tyndale-Biscoe, C.H., Hearn, J.P. \& Renfree, M.B. (1974) Control of reproduction in macropodid marsupials. J. Endocr. 63, 589-614.

Von der Borch, S.M. (1963) Unilateral hormone effect in the marsupial Trichosurus vulpecula. J. Reprod. Fert. 5, 447-449.

Ward, K.L. \& Renfree, M.B. (1984) Effects of progesterone on parturition in the tammar, Macropus eugenii. J. Reprod. Fert. 72, 21-28.

Young, I.R. \& Renfree, M.B. (1979) The effects of corpus luteum removal during gestation on parturition in the tammar wallaby (Macropus eugenii). J. Reprod. Fert. 56, 249-254. 